\title{
Effect of exogenous gonadotrophin (PMSG) on the antral follicle population in the sheep
}

\author{
H. M. Dott, Mary F. Hay*, D. G. Cran and R. M. Moor \\ A.R.C. Institute of Animal Physiology, Animal Research Station, 307 Huntingdon Road, \\ Cambridge CB3 OJQ, U.K.
}

\begin{abstract}
Summary. Follicles were obtained from the ovaries of four groups of 15 ewes. Ewes in the control group were ovariectomized on the 12th day of the oestrous cycle. The other ewes were all given PMSG on the 12th day of the cycle; some were ovariectomized 24 or $40 \mathrm{~h}$ later, the others were given prostaglandin followed by hCG and were ovariectomized 6 or $12 \mathrm{~h}$ after the hCG injection. All follicles $>2 \mathrm{~mm}$ in diameter were measured and examined macroscopically for signs of atresia. Some were subjected to detailed morphological examination, the pattern of steroid secretion was determined in others. All the evidence from these three approaches suggested that, in vivo, reversal of the atretic process ('rescue') plays no part in the increase in the number of follicles observed following administration of PMSG.
\end{abstract}

\section{Introduction}

Throughout most of the oestrous cycle each ovary of the mature sheep contains about 10 follicles $>2 \mathrm{~mm}$ in diameter of which up to two-thirds are undergoing atresia (Brand \& de Jong, 1973). At the end of the normal cycle only one or two follicles will expand and ovulate; however, if exogenous gonadotrophin is administered during the luteal phase, approximately 10 follicles will ovulate.

There are three ways in which exogenous gonadotrophins might stimulate the development of additional follicles: (i) follicles could be recruited into the growing population (i.e. follicles $>2$ $\mathrm{mm}$ in diameter) by acceleration of growth of smaller follicles; (ii) follicles that were about to become atretic could be stimulated to further development instead; (iii) the process of atresia may be reversed and follicles that were already exhibiting some degree of atresia could be 'rescued' and stimulated to grow and ovulate.

These possibilities are not mutually exclusive, indeed there is evidence in support of all of them: gonadotrophins (FSH) stimulate follicles to grow, prevention and reversal of atresia have been observed in the mouse in vivo (Peters, Byskov, Himelstein-Braw \& Faber, 1975; Byskov, 1979) and we have shown that atretic ovine follicles undergo morphological regeneration in culture (Hay, Moor, Cran \& Dott, 1979).

The experiments described in this paper were designed to find out if follicles are rescued by PMSG. This was investigated by observing the effect of the gonadotrophin on the number of follicles in the ovary, their morphology and the pattern of steroid secretion.

\section{Animals}

\section{Materials and Methods}

Follicles were dissected from the ovaries of Welsh Mountain sheep using a procedure already described (Moor, Hay, McIntosh \& Caldwell, 1973). From the 15 control animals, follicles were obtained on the 12 th day of the cycle. The 45 experimental ewes received 1000 i.u. PMSG (Folligon: Intervet Laboratories Ltd, Cambridge) on Day 12: 15 of these sheep were ovariectomized $24 \mathrm{~h}$ later (24-h PMSG group) and a further 15 after an interval of $40 \mathrm{~h}$ (40-h 
PMSG group). To obtain follicles at known times after the action of hCG, the remaining 15 animals were treated with $100 \mu \mathrm{g}$ prostaglandin analogue (ICI 80,996: ICI, Macclesfield, Cheshire) at $48 \mathrm{~h}$ and with 500 i.u. hCG (Luthormone LH: Intervet Laboratories Ltd, Cambridge) at $72 \mathrm{~h}$ after PMSG. Six of these animals were ovariectomized $6 \mathrm{~h}$ after the hCG injection (6-h hCG group) and 9 after $12 \mathrm{~h}$ (12-h hCG group).

\section{Follicles}

The diameter of the follicles was measured. All follicles $>2 \mathrm{~mm}$ diameter from 11 control sheep, 7 of the 24-h PMSG and 3 of the 40-h PMSG ewes were fixed and stained for histological or ultrastructural examination. A random sample of smaller follicles (1-1.9 mm diameter) from the control and 24-h PMSG sheep was also fixed and examined histologically. Follicles from an additional 4 sheep were examined with the electron microscope; these sheep were ovariectomized $6 \mathrm{~h}$ after injection of PMSG (14 follicles), $12 \mathrm{~h}$ after PMSG (15 follicles) and $18 \mathrm{~h}$ after PMSG (16 follicles). For histological examination, follicles were fixed in Bouin's fluid, embedded in paraffin wax and stained with haematoxylin and chromatrope. For examination of the ultrastructure, follicles were fixed intact and processed as described by Hay, Cran \& Moor (1976).

All the non-atretic follicles $>2$ mm diameter from 4 of the 24-h PMSG ewes and all the nonatretic follicles $>3.4 \mathrm{~mm}$ in diameter from the $12 \mathrm{~h} \mathrm{hCG}$ ewes were cultured for $24 \mathrm{~h}$ (Moor, 1973). The concentrations of unconjugated oestrogen, testosterone and progesterone were determined in the culture fluid by radioimmunoassay (Moor, 1977). The culture fluid from 99 non-atretic and 25 atretic follicles $>2.9 \mathrm{~mm}$ diameter obtained from an additional group of untreated sheep was also assayed for these steroids.

The follicular fluid from all non-atretic follicles $>3.5 \mathrm{~mm}$ in diameter from ten $40-\mathrm{h}$ PMSG ewes was assayed for androstenedione in addition to the other 3 steroids after extraction with diethyl ether (Moor, Hay, Dott \& Cran, 1978).

The steroid content of follicles from 6-h hCG ewes is not presented because at this time follicles are changing from oestrogen to progesterone production and this would obscure any heterogeneity in the population that might be attributed to rescue.

The limits of sensitivity and the between-assay coefficients of variation for the assays were $10 \mathrm{pg}$ and $7 \%(n=11)$ for oestrogen, $15 \mathrm{pg}$ and $8 \%(n=11)$ for testosterone and $30 \mathrm{pg}$ and $12 \%(n=11)$ for progesterone (Moor, 1977) and $5 \mathrm{pg}$ and $9 \%(n=20)$ for androstenedione (Moor et al., 1978).

\section{Statistical analyses}

The data on the ratio of atretic to non-atretic follicles was analysed by $\chi^{2}$ and by using a $t$ test on the proportion transformed to angles. The level of significance was similar in both tests. The mean numbers of follicles in the different groups were compared by $t$ test; the proportions in different size categories (after transforming to angles) were also compared by a $t$ test.

The results of the steroid determinations were analysed both as absolute steroid concentration and as a proportion of the total steroid content (after transforming to angles) using a $t$ test. Third and fourth moment statistics were used to test for normality of distribution where possible. The 99 non-atretic follicles from the additional untreated ewes and the 100 follicles from the 40-h PMSG ewes were subjected to cluster analysis (Davies, 1978) using the proportions of testosterone, oestrogen and progesterone for follicles from untreated sheep; androstenedione was included for the 40-h PMSG group.

\section{Number and size of follicles (Table 1)}

\section{Results}

In the control animals $74 \%$ of the follicles over $2 \mathrm{~mm}$ in diameter were between 2 and 2.9 $\mathrm{mm}$ in diameter; $24 \mathrm{~h}$ after PMSG the proportion of follicles in this size category had decreased 
to $50 \%$ and that in the $3-3.9-\mathrm{mm}$ range had increased from 6.6 to $24 \%$. In the next $16 \mathrm{~h}(40-\mathrm{h}$ PMSG sheep), the $3-3.9 \mathrm{~mm}$ follicles represented only $13 \%$ of the population and the proportion $>3.9 \mathrm{~mm}$ in diameter had increased to $38 \%$. The largest follicles obtained were $10-10.9 \mathrm{~mm}$ in diameter and the number of follicles in the larger sizes increased particularly after administration of hCG.

Table 1. Number and sizes (mean \pm s.e.m.) of follicles in sheep given PMSG on Day 12 of the cycle

\begin{tabular}{|c|c|c|c|c|c|}
\hline \multirow[b]{2}{*}{ Group* } & \multirow{2}{*}{$\begin{array}{l}\text { Total no. } \\
\text { of sheep }\end{array}$} & \multirow{2}{*}{$\begin{array}{l}\text { No. of } \\
\text { follicles }\end{array}$} & \multicolumn{3}{|c|}{ Proportions according to diameter } \\
\hline & & & $2-2.9 \mathrm{~mm}$ & $3-3.9 \mathrm{~mm}$ & $>3.9 \mathrm{~mm}$ \\
\hline Control & 15 & $18 \cdot 8 \pm 2.6$ & $0.74 \pm 0.003$ & $0.07 \pm 0.003$ & $0.17 \pm 0.003$ \\
\hline 24-h PMSG & 15 & $24 \cdot 1 \pm 3 \cdot 2$ & $0.5 \pm 0.004$ & $0.24 \pm 0.001$ & $0.23 \pm 0.004$ \\
\hline 40-h PMSG & 15 & $25.6 \pm 3.7$ & $0.47 \pm 0.002$ & $0.13 \pm 0.002$ & $0.38 \pm 0.001$ \\
\hline $6-+12-h \mathrm{hCG}$ & 15 & $17 \cdot 6 \pm 1.8$ & $0.31 \pm 0.003$ & $0.042 \pm 0.002$ & $0.61 \pm 0.004$ \\
\hline
\end{tabular}

* See text.

\section{Proportion of atretic follicles (Table 2)}

In untreated animals the proportion of follicles that was non-atretic was approximately $50 \%$ in all size categories (Table 2). The figures for 1-1.9-mm diameter follicles were random samples obtained from the same ovaries as the larger follicles and do not represent complete follicle populations. Between 24 and $40 \mathrm{~h}$ after PMSG there was no change in the proportion of nonatretic follicles in the $2-2.9 \mathrm{~mm}$ category (i.e. a reduction in number of non-atretic follicles) but the proportion increased to approximately $80 \%$ in the $3-3.9 \mathrm{~mm}$ follicles (i.e. the number of atretic follicles did not change).

Table 2. Proportion of non-atretic follicles in sheep treated with PMSG on Day 12 of the cycle

\begin{tabular}{lcccc}
\hline & & \multicolumn{3}{c}{ Proportions according to diameter } \\
\cline { 2 - 4 } Group & $\begin{array}{c}\text { No. of } \\
\text { sheep }\end{array}$ & $1-1.9 \mathrm{~mm}$ & $2-2.9 \mathrm{~mm}$ & $>3.0 \mathrm{~mm}$ \\
\hline Control & 11 & $0.49 \pm 0.0009$ & $0.50 \pm 0.003$ & $0.46 \pm 0.007$ \\
24-h PMSG & 7 & $0.57 \pm 0.008$ & $0.38 \pm 0.007$ & $0.76 \pm 0.002$ \\
40-h PMSG & 3 & - & $0.36 \pm 0.008$ & $0.90 \pm 0.027$ \\
\hline
\end{tabular}

\section{Morphology}

Follicles in ovaries from the sheep which had not received PMSG could be easily separated into 2 categories (non-atretic and atretic) macroscopically, histologically and on ultrastructural criteria as described by Hay et al. (1976).

Large $(>3.5 \mathrm{~mm}$ ) follicles from sheep treated with PMSG $24 \mathrm{~h}$ and $40 \mathrm{~h}$ before ovariectomy became progressively more difficult to classify by gross criteria, but atretic and non-atretic follicles were clearly distinguishable histologically and ultrastructurally. In a very few apparently non-atretic follicles, fibrin, a substance usually found only in atretic follicles, was observed in the antrum; no other indications of atresia, such as phagosomes or other evidence of phagocytosis, were observed in the non-atretic follicles and gap junctions were always present.

\section{Steroids}

The follicles obtained $24 \mathrm{~h}$ after PMSG and those from the untreated sheep contained insufficient fluid for accurate analysis. Therefore they were cultured and the amounts of oestrogen, testosterone and progesterone produced $/ \mathrm{mg}$ follicular tissue during $24 \mathrm{~h}$ culture were 


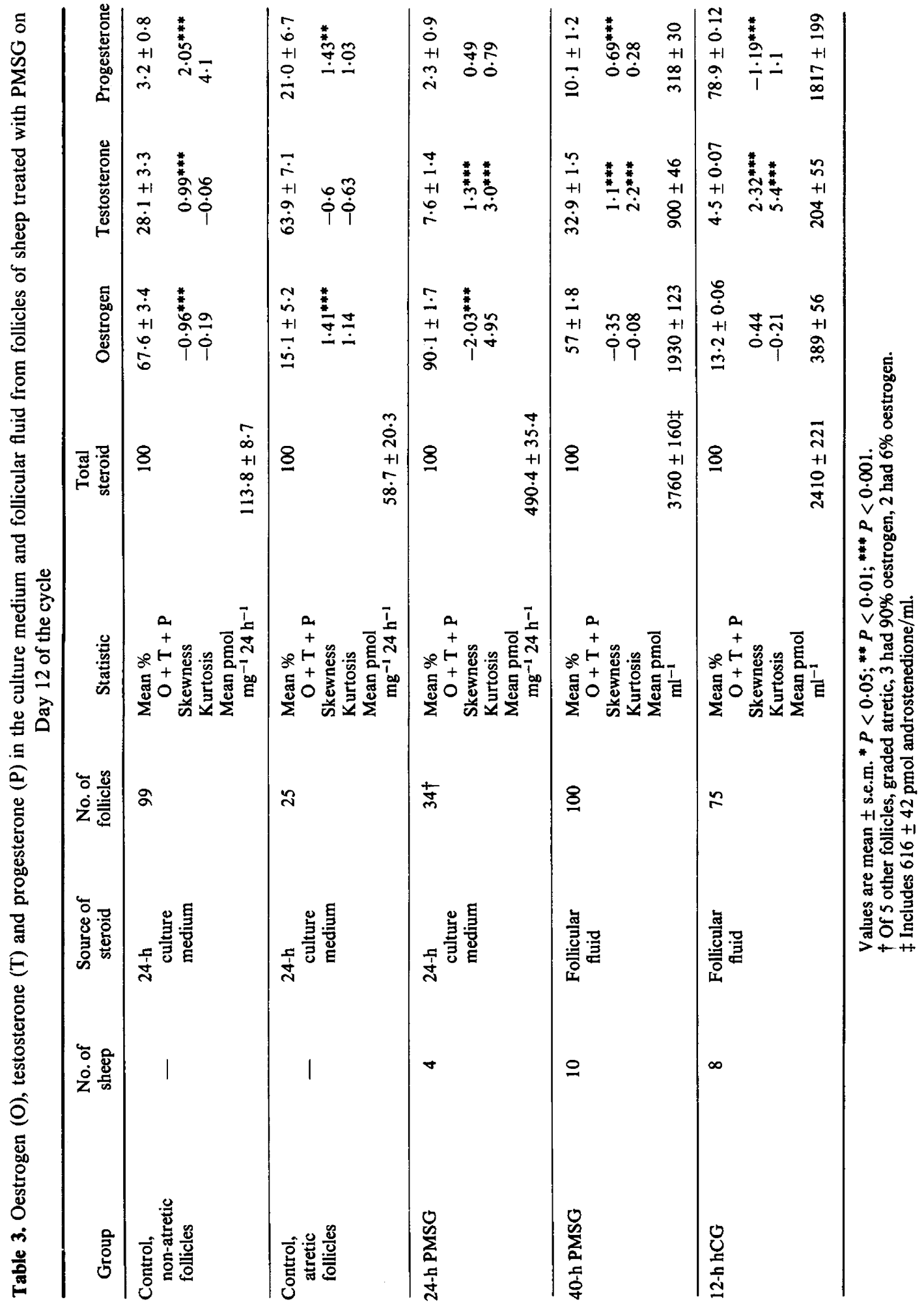


added together; the contribution of the individual steroids is expressed as a percentage of this total in Table 3. It has been shown that the proportion of steroids in follicular fluid and culture medium is the same (Moor et al., 1978). Therefore valid comparison can be made between the proportion of steroids in the culture medium from the follicles from untreated sheep and 24-h PMSG ewes, and the follicular fluid from the 40-h PMSG and 12-h hCG ewes.

In non-atretic follicles from untreated sheep oestrogen is the predominant hormone and in atretic follicles testosterone is most abundant (Moor et al., 1978). The steroid production of the 99 non-atretic follicles was not normally distributed but the follicles could be divided into 6 groups $(\mathrm{N}=34,22,12,8,7,6)$ by cluster analysis. The steroid production of each group was normally distributed and the total steroid produced by each group differed significantly from the others; oestrogen was the most abundant steroid produced by all groups. Follicles from the $24-\mathrm{h}$ PMSG ewes produced more steroid than any of these groups $(P<0.001$ in all cases). The proportions of oestrogen and testosterone in the 34 follicles from the 24-h PMSG ewes were not normally distributed (both were skew and kurtotic) but only 3 follicles had more than 10\% testosterone and less than $78 \%$ oestrogen; the highest testosterone was $31 \%$ and the lowest oestrogen $50 \%$ (the same follicle).

In the fluid of follicles obtained $40 \mathrm{~h}$ after PMSG oestrogen was the predominant steroid. Although the total steroid and the proportion of oestrogen was normally distributed none of the hormone concentrations was distributed normally (skewed and kurtotic). If the follicles were divided into 2 populations on the basis of the concentration of androstenedione, those with $<530$ pmol androstenedione/ml (54/100 follicles) had higher concentrations of oestrogen and progesterone than those with $>700 \mathrm{pmol}$ androstenedione $/ \mathrm{ml}$ (34/100 follicles). Within these groups the distribution of the steroid concentration was normal but, even in the high androstenedione group, oestrogen was the predominant hormone. These follicles could be divided into 4 groups $(N=34,29,17,8)$ by cluster analysis; the group of 8 follicles contained less steroid than did those in the other 3 groups $(P<0.001$ in all cases), in all of which oestrogen was the most abundant hormone.

Progesterone was the most abundant hormone in follicles from the $12-\mathrm{h} \mathrm{hCG}$ group, but its proportion was not normally distributed.

\section{Discussion}

In the absence of PMSG all growing follicles except the one or two destined to ovulate will continue to grow until they become atretic, whereupon they gradually shrink and leave the population under consideration. When PMSG is given, the number of non-atretic follicles $>3.0 \mathrm{~mm}$ in diameter increases while the number of non-atretic follicles $2.0-2.9 \mathrm{~mm}$ in diameter decreases; furthermore the number of atretic follicles in both size categories remains the same as in untreated sheep (see Table 4). Strictly speaking, the data refer only to the follicle populations in this study since the observed differences did not reach statistical significance.

Table 4. Mean number of non-atretic (NA) and atretic (A) follicles per ewe before and after injection of PMSG

\begin{tabular}{|c|c|c|c|c|c|c|}
\hline \multirow{2}{*}{$\begin{array}{c}\text { Follicle } \\
\text { diameter } \\
(\mathrm{mm})\end{array}$} & \multicolumn{2}{|c|}{ Before PMSG } & \multicolumn{2}{|c|}{$24 \mathrm{~h}$ after PMSG } & \multicolumn{2}{|c|}{$40 \mathrm{~h}$ after PMSG } \\
\hline & NA & A & NA & A & NA & A \\
\hline$>3 \cdot 0$ & $2 \cdot 4$ & 2.4 & 9 & 3 & $10 \cdot 8$ & $1 \cdot 2$ \\
\hline $2 \cdot 0-2.9$ & $7 \cdot 1$ & $7 \cdot 1$ & 4.8 & $7 \cdot 2$ & $4 \cdot 6$ & $7 \cdot 4$ \\
\hline Total $>2.0 \mathrm{~mm}$ & $9 \cdot 5$ & $9 \cdot 5$ & $13 \cdot 8$ & $10 \cdot 2$ & $15 \cdot 4$ & $8 \cdot 6$ \\
\hline Change in total no. after PMSG & - & - & $+4 \cdot 3$ & $+0 \cdot 7$ & +5.9 & -0.9 \\
\hline
\end{tabular}


As outlined in the 'Introduction', there are three possible mechanisms by which PMSG might act, namely, increased rate of entry of follicles into $>2 \mathrm{~mm}$ size category, prevention of normal occurrence of atresia or reversal of the atretic process. Three experimental approaches have been used in this study to determine whether rescue of atretic follicles plays a major role in the action of PMSG. Using the morphological approach, no clear evidence of rescue could be found despite examination of follicles at a wide range of times (6-40 h) after injection of PMSG. Very few follicles showed any fine structural details which distinguished them from non-atretic follicles taken from untreated sheep. If rescue were occurring one might expect to see evidence of phagocytosis, such as was seen in vitro (Hay et al., 1979), but no such activity was observed. Furthermore, when regeneration of the granulosa layer of atretic follicles occurred in vitro, gap junctions were largely absent; in vivo, no follicles other than those that were clearly atretic displayed this characteristic. These findings are in sharp contrast to those of Byskov (1979) who has reported ultrastructural evidence of rescue of atretic follicles in mice, $24 \mathrm{~h}$ after injection of PMSG.

The second indicator used in this study for the occurrence of rescue was to examine the profile of follicular steroid secretion. The steroid pattern in follicles stimulated by PMSG was in all cases dominated by oestrogen. It has previously been shown that oestrogen is the predominant steroid secreted in vitro by large non-atretic follicles, whereas atretic follicles, which invariably regenerate morphologically in culture, secrete virtually no oestrogen but high levels of androgen and progesterone (Moor et al., 1978; Hay et al., 1979). Further work has shown that the atretic follicles cannot be stimulated to produce oestrogen in culture by including FSH, LH or oestrogen in the culture fluid either singly or in combination ( $R$. M. Moor, unpublished observations). The follicles recovered $40 \mathrm{~h}$ after PMSG could be divided into 2 populations but neither of these populations had the same steroid profile as was observed in follicles rescued in vitro (Hay et al., 1979); furthermore, neither the 24-h PMSG follicles nor the 12-h hCG follicles could be divided into 2 populations on the basis of their steroid profiles. As the non-atretic follicles of untreated sheep do not constitute a normally distributed population the lack of normal distribution among the 40-h PMSG follicles is of doubtful value as evidence of recovery from atresia even though this group could be divided into 2 populations. Thus the evidence from the steroids supports that derived from morphology that PMSG does not rescue follicles in vivo.

The third line of evidence is derived from a consideration of follicle populations. After PMSG stimulation the number of non-atretic follicles $>2 \mathrm{~mm}$ in diameter increased substantially but this was not accompanied by any decrease in the number of atretic follicles (see Table 4). If rescue were the mechanism by which PMSG acted, it would be necessary to postulate two processes. In the larger group of atretic follicles $(>2 \mathrm{~mm})$, cellular degeneration would have to be halted and growth initiated. In addition, small $(<2 \mathrm{~mm})$ atretic follicles would have to increase in size without undergoing regeneration in order to maintain the observed stable number of atretic follicles. The difficulties inherent in this last hypothesis, together with our observations on morphology and steroid function, lead us to conclude that reversal of atresia (rescue) does not play a major role in ovarian stimulation by PMSG in the sheep.

If rescue is not responsible for ovarian stimulation in the sheep it is probable that one or both of the other possibilities are involved. To assess their relative importance data will have to be obtained on the effect of PMSG on the rate of entry of follicles into the $>2 \mathrm{~mm}$ non-atretic category and also on the rate of loss from this population. If PMSG acts by preventing atresia, it follows that fewer follicles will leave the non-atretic pool to become atretic, and there would have to be a simultaneous counterbalancing decrease in the rate of loss of follicles from the $>2 \mathrm{~mm}$ atretic category. 


\section{References}

Brand, A. \& de Jong, W.H.R. (1973) Qualitative and quantitative micromorphological investigations of the tertiary follicle population during the oestrous cycle in sheep. J. Reprod. Fert. 33, 431-439.

Byskov, A.G. (1979) Atresia. In Ovarian Follicular Development and Function, pp. 41-57. Eds A. R. Midgley \& W. A. Sadler. Raven Press, New York.

Davies, W.G. (1978) Cluster analysis applied to the classification of postures in the chilean flamingo (Phoenicapterus chilersin). Anim. Behav. 26, 381388.

Hay, M.F., Cran, D.G. \& Moor, R.M. (1976) Structural changes occurring during atresia in sheep ovarian follicles. Cell Tissue Res. 169, 515-529.

Hay, M.F., Moor, R.M., Cran, D.G. \& Dott, H.M. (1979) Regeneration of atretic ovarian follicles in vitro. J. Reprod. Fert. 55, 195-207.
Moor, R.M. (1973) Oestrogen production by individual follicles explanted from ovaries of sheep. J. Reprod. Fert. 32, 545-548.

Moor, R.M. (1977) Sites of steroid production in ovine Graafian follicles in culture. J. Endocr. 73, 143-150.

Moor, R.M., Hay, M.F., McIntosh, J.E.A. \& Caldwell, B.V. (1973) Effect of gonadotrophins on the production of steroids by sheep ovarian follicles cultured in vivo.J. Endocr. 58, 599-611.

Moor, R.M., Hay, M.F., Dott, H.M. \& Cran, D.G. (1978) Macroscopic identification and steroidogenic function of atretic follicles in sheep. J. Endocr. 77, 309-318.

Peters, H., Byskov, A.G., Himelstein-Braw, R. \& Faber, M. (1975) Follicular growth: the basic event in the mouse and human ovary. J. Reprod. Fert. 45, 559566.

Received 2 January 1979 